\title{
Effects of Polyethylene Glycol on the Mechanical Properties of Medium Carbon Low Alloy Steel
}

\author{
I. M. Momoh ${ }^{1 *}$, B. J. Bamike ${ }^{1}$, A. M. Saliu ${ }^{1}$, O. A. Adeyemi ${ }^{2}$ \\ ${ }^{1}$ Department of Metallurgical Engineering, Kogi State Polytechnic, Lokoja, Nigeria. \\ ${ }^{2}$ QA/QC \& Safety Unit, Engineering Materials Development Institute, Akure, Nigeria.
}

\begin{abstract}
The effect of polyethylene glycol $\left[\mathrm{H}\left(\mathrm{OCH}_{2} \mathrm{CH}_{2}\right)_{n} \mathrm{OH}\right]$ as quenchant was studied with a view to investigate the mechanical properties and microstructural evaluation of steel. The test samples were subjected to a conventional heat treatment process followed by quenching using prepared polymer solution with a definite proportion. The samples were characterized using a microhardness tester and universal tensile machine for the mechanical properties, metallurgical microscope was used in analyzing their structural re-orientation. From the result, it was observed that the hardness increment of the quenched samples conform to literature review as there was also a rise in the tensile properties. This though, was at the expense of their ductility. The micrographs were found to have justified the reason for the increment recorded in some of the mechanical properties, as it displayed a high proportion of the martensitic phase.
\end{abstract}

KEYWORDS: Hardness, Impact Energy, Polyethylene Glycol, Quenching

[Received May 27 2015; Revised November 42015 \& December 3 2015; Accepted December 20 2015]

\section{INTRODUCTION}

Medium carbon steel (as-rolled) most often does not meet the requirements for automobile and industrial applications where high hardness and strength are required; mainly due to their limitations in some mechanical properties. To meet these requirements, several methods of heat treatment techniques have been adopted with a view to manipulate its structure and thus widen its scope of application (Momoh, 2012). Among others, this technique includes the conventional normalizing process which requires the cooling of the materials in natural air to enhance the relief of stress that might have been induced during the manufacturing process; annealing, as it involves the cooling of the material in the furnace after heating to a predetermined austenitic temperature. Other conventional techniques are quenching and tempering operations (Khanna, 2009).

In order to improve on the hardness and strength of steel, quenching operation has been adopted (Higgins, 2004). In most cases however, it is observed that it is usually at the expense of its ductility (Martin et al, 1997). Quenching operation involves the heating of material to austenitic state and allow it to cool rapidly (Quenching) in a defined cooling medium such that the atomic arrangement within the metal will be forced to undergo a re-orientation and then results to the desired properties.

Several media are being used in the cooling of steel during quenching operations which among others, include water (Ahmed et al, 2014), polymer its salt hybrid solution (Ramesh and Pradhu, 2015). The selection of cooling medium depends, to a large extent, on the desired properties and

*Corresponding author's e-mail address: rhodave2011@gmail.com application (Martin et al, 1997; Higgins, 2004; Momoh, 2012). Some of these media that have been conventionally used includes water, brine and oil. Recently however, the use of polymer has begun to gain relevance in the quenching operation ferrous metals.

Some researchers have investigated the effect of polymer quenchant on the properties of steel (Eshraghi-Kakhki et al, 2011; Ahmed, 2011). However most of these studies were on low carbon steel with a view to improve the strength and justify it with the developed structures. Thorough analysis of the mechanical properties of medium carbon steel in polymer is of high importance in the industrial sector and that serves as a reason for this study.

\section{MATERIALS AND METHOD}

\section{A Materials and Equipment}

With the aim of determining the response of steel to polymer (Polyethylene glycol) quenching operation, a commercially available carbon steel of chemical composition shown in Table 1 was procured. Polyethylene glycol $\mathrm{H}\left(\mathrm{OCH}_{2} \mathrm{CH}_{2}\right)_{\mathrm{n}} \mathrm{OH}$ [where $\mathrm{n}$ represent the average number of oxyethylene groups] - was also procured to serve as the quenchant. The equipment used to carry out the experiment includes: muffle furnace, hack saw, bench vice, spectrometer, tensile testing machine, hardness machine, and scanning electron microscope.

\section{B Method}

The as-received $12 \mathrm{~mm}$ diameter rod was firstly taken to Universal Steel Ltd, Lagos for spectrometric analysis where it doi: http:/ /dx.doi.org/10.4314/njtd.v12i2.5 
was confirmed to contain $0.38 \%$ carbon content. The bulk rod was machined to tensile configuration of $40 \mathrm{~mm}$ gauge length and $5 \mathrm{~mm}$ diameter; and impact configurations of $80 \mathrm{~mm}$ length and $5 \mathrm{~mm}$ diameter with $2 \mathrm{~mm}$ notch. These operations were carried out using medium size lathe machine while pieces were also cut for microhardness evaluation. Four sample sets were machined each for the predetermined three different Polyethylene Glycol (PEG) mixture proportion and for the control. The samples were initially normalized by heating to austenitic region and allowed to cool in air; this is to annul the mechanical history of the machined specimen (Momoh, 2012) and this serves as the initial microstructure for the experiment. Subsequently, all samples were heat treated at $900{ }^{\circ} \mathrm{C}$ in a muffle furnace and held for 60 minutes prior to rapid cooling in prepared polymer mixtures of 20,40 and $60 \%$ of Polyethylene glycol (PEG). The treated samples were designated to avoid mix-up in the course of characterization as presented in Table 2. The developed structure were characterized and analysed.

Table 1: Chemical composition of the steel used in this experiment.

\begin{tabular}{lllllll}
\hline Elements & $\mathbf{C}$ & $\mathbf{S i}$ & $\mathbf{S}$ & $\mathbf{P}$ & $\mathbf{M n}$ & $\mathbf{N i}$ \\
\hline Composition & 0.3800 & 0.1630 & 0.0399 & 0.0301 & 0.7425 & 0.0911 \\
\hline Elements & $\mathbf{C r}$ & $\mathbf{M o}$ & $\mathbf{V}$ & $\mathbf{C u}$ & $\mathbf{W}$ & $\mathbf{A s}$ \\
\hline Composition & 0.0555 & 0.00180 & 0.0029 & 0.3031 & 0.0003 & 0.0060 \\
\hline Elements & $\mathbf{S n}$ & $\mathbf{C o}$ & $\mathbf{A l}$ & $\mathbf{C a}$ & $\mathbf{Z n}$ & $\mathbf{F e}$ \\
\hline Composition & 0.0230 & 0.0094 & 0.0019 & 0.0002 & 0.0037 & 98.1858 \\
\hline
\end{tabular}

Table 2: Sample's designation.

\begin{tabular}{cc}
\hline Label & Polymer $: \mathbf{H}_{\mathbf{2}} \mathbf{O}$ \\
\hline Sample A & Normalized \\
Sample B & $3: 7$ \\
Sample C & $2: 8$ \\
Sample D & $1: 9$ \\
\hline
\end{tabular}

\section{Results AND Discussion}

A Effects of Polymer Quenching on the Microhardness of Medium Carbon Steel

Figure 1 shows the hardness plots of the steel and its improvement after quenching operation was carried out. The untreated sample (Sample A) was observed to have the least hardness value thus indicating its unreliability in certain applications where high hardness is required. The effects of the quenching operation were explicit in other samples as they all exhibited higher hardness values. Sample $\mathrm{C}$ which was quenched in 2:8 polymer: water mixture respectively was observed to exhibit the highest hardness value of $431.7 \mathrm{HV}$ in comparison to the control sample that possess $238.9 \mathrm{HV}$ thus translating into $80.7 \%$ increment. The reason for this expected increment has been attributed to the very short time expended in bringing the temperature of the heat treated sample to a lower temperature such that no reaction would occur within the atoms of the material during the quenching process (Ndaliman, 2006).

\section{$B \quad$ Effects of Polymer Quenching on the Impact Energy of Medium Carbon Steel}

A progression in the impact strength with respect to the quenching media proportion was observed in the result (see Figure 2). The control sample as conventionally expected, displayed the least strength, while the quenched sample displayed interesting values that indicate that the proportion of the mixture for quenching is a factor in determining the impact strength of steel. Sample D quenched in 1:9 polymer:water exhibited the highest value indicating that it has the highest tendency to withstand sudden shock at a predefined condition prior to failure.

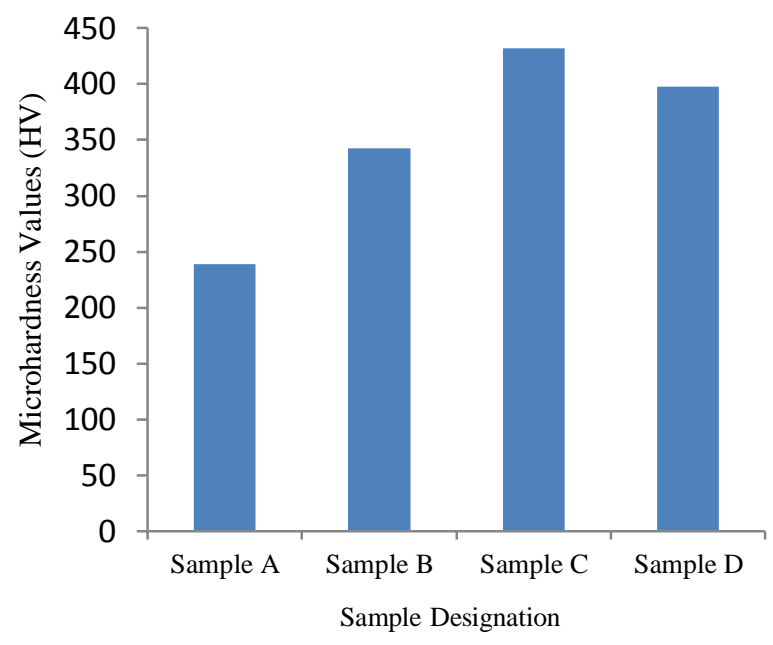

Figure 1: Variation of hardness to quenchant proportion.

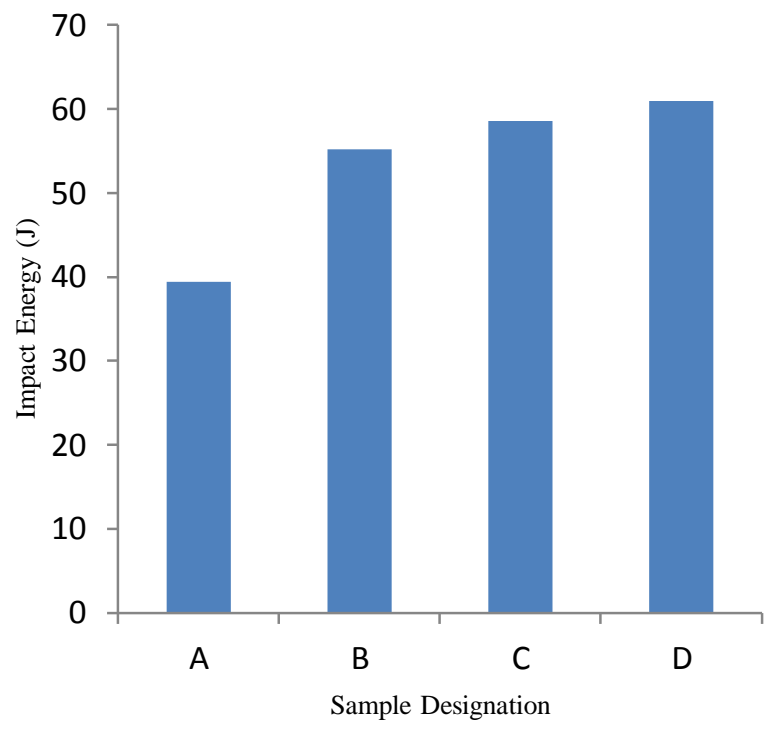

Figure 2: Variation of impact strength to quenching media ratio.

C Effects of Polymer Quenching on the Tensile Properties of Medium Carbon Steel

Figures 3 and 4 are the plots showing the tensile properties of the quenched and unquenched steel. The result of the ultimate tensile strength (UTS) for the unquenched steel corresponds to findings in the literature (Higgins, 2004; Eshraghi-kakhki et al, 2011). While samples C and D were observed to display high UTS values (See Figure 4.3), sample B however showed a reduction in comparison to the control sample. The reason for this could be attributed to an emergence of crack (which ensues as a result of high rate of 
quenching in the medium) on the sample during quenching operation. Summarily, sample D quenched in 1:9 mixture of polymer and water respectively displayed the highest value for UTS indicating its ability to withstand higher load than others. This however, is a risk not worth taking as its ductility had drastically reduced as depicted by the results in Figure 4. Here, all quenched sample were observed to have sacrificed their ductility for strength and hardness as the unquenched possess the highest extension prior to failure thus indicating its high endurance limit at fixed load. The least 'extension at break' value displayed by sample D showed that it is brittle and its failure will be catastrophic as there will be little or no notification prior to fracture.

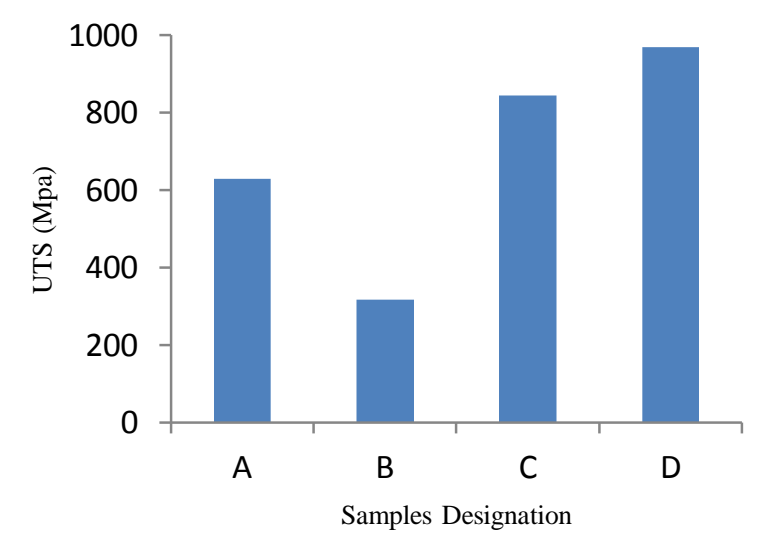

Figure 3: Plot of ultimate tensile strength versus the designation.

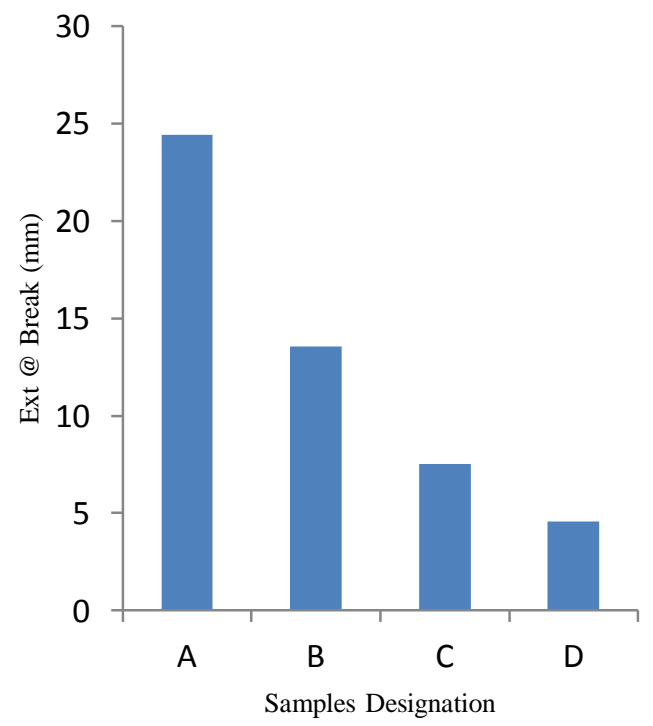

Figure 4: plot of extension of the steel at break versus the sample designation.

\section{Effects of Polymer Quenching on the Microstructure of Medium Carbon Steel}

The microstructures obtained are shown in Plates $1-4$. The microstructure produced by the control sample consists of pearlitic-ferritic structure while the microstructures produced by the processes consist of a finely distributed ferritemartensite microstructure. The strong deformable second phase consists predominantly martensite with some retained austenite. Martensite provides the strength in the steel which justifies the improvement in some of the mechanical properties as earlier discussed; whereas the ferrite provides the ductility. The strong second phase is dispersed in a soft ductile ferrite matrix.

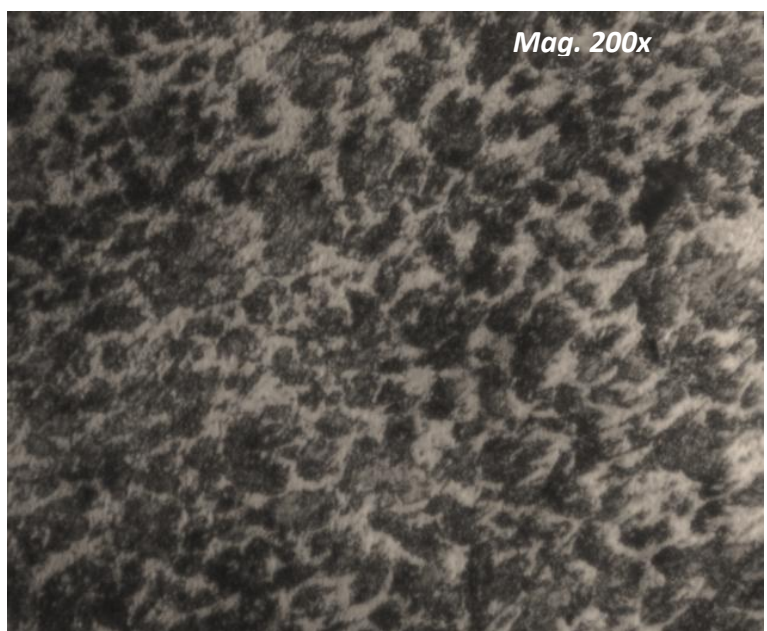

Plate1: Microstructure of sample A showing pearlite (dark region) in ferrite (grey region) matrix.

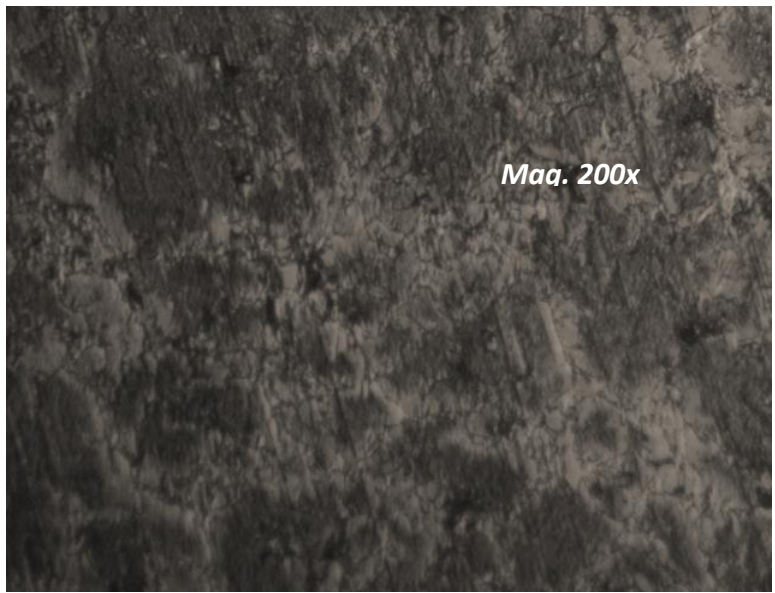

Plate 2: Microstructure of sample B showing martensite (dark region) in ferrite (grey region) matrix.

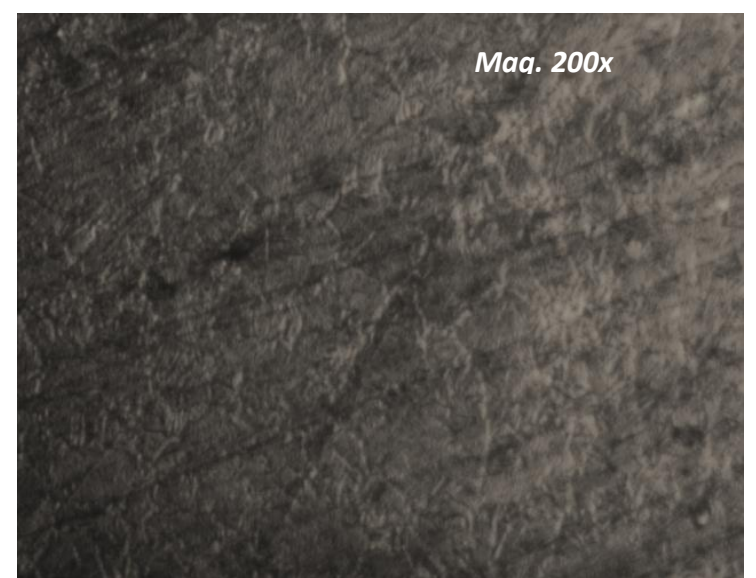

Plate 3: Microstructure of sample $\mathrm{C}$ showing martensite (dark region) in ferrite (grey region) matrix. 


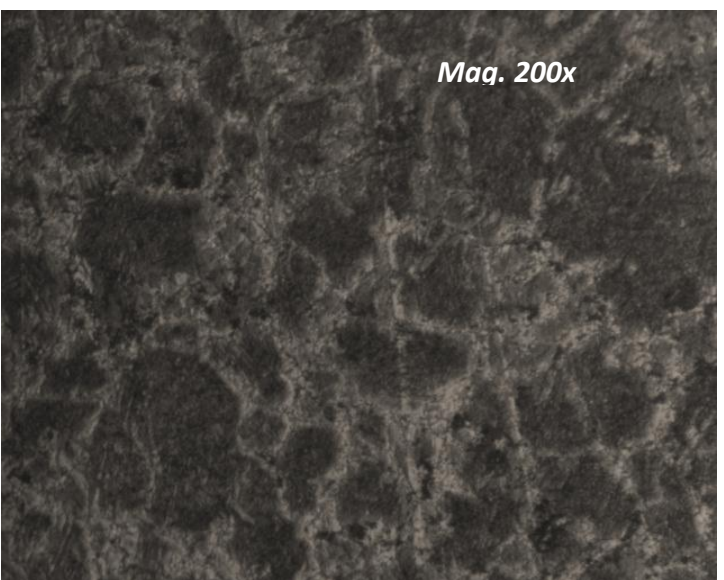

Plate 4: Microstructure of sample D showing coarse martensite (dark region) in ferrite (grey region) matrix.

\section{CONCLUSION}

This study tends to investigate the mechanical properties and microstructural evaluation of quenched medium carbon steel in polyethylene glycol. After characterization, the results show that;

- The hardness increases with decrease in the polymer concentration and increase in the water concentration in the quenching medium

- The impact energy displays an inverse relationship with the polymer concentration

- The ultimate tensile strength also decreases as the polymer in the mixture increases

- The ductility however, was observed to be sacrificed for the strength as it decreases with decrease in the volume of the polymer

- The micrographs justify the reason for the increment recorded in the mechanical properties as it displayed high proportion of martensitic phase.

\section{REFERENCES}

Ahmed D.; Wright J., Adebisi A., Aremu I.N., Yahaya T. and Quita da Fonseca J. (2014). Assessment of Deformation Twinning in Cold Rolled Austenitic Stainless Steels with Electron Back Scatter Diffraction. Nigerian Journal of Technological Development, 11(1): 7-11.

Ahmed O. J. (2011). Study the effect of polymer solution and oil quenchants on hardening automotive camshaft. Journal of Thi-Qar University. 6 (2):134 - 146.

Eshraghi-Kakhki M., Golozar M. A., Kermanpur A. (2011). Application of polymeric quenchant in heat treatment of crack-sensitive steel mechanical parts: Modeling and experiments. Materials and Design. 32:2870-2877.

Higgins A. R. (2004). Engineering Metallurgy - Part 1 Applied Physical Metallurgy. $7^{\text {th }}$ Edition. Edward Arnold. England.

Khanna O. P. (2009). Material Science and Metallurgy. Dhanpat Rai Pub (P) Ltd.

Martin J. W.; R. D. Doherty and B. Cantor (1997). Stability of Microstructure in Metallic Systems ( $2^{\text {nd }}$ edition). Cambridge: Cambridge University Press, UK.

Momoh I. M. (2012). Microstructures, Corrosion and Mechanical Behavior of Dual Phase Medium Carbon Low Allow Steels. [Thesis]. Nigeria. University of Technology, Akure. 56 - 68.

Ndaliman M. B. (2006). An Assessment of Mechanical properties of Medium Carbon Steel under Different Quenching Medium. AU J.T. 10(2):100-104.

Ramesh G. and Prabhu K.N. (2015). Comparative Study of Wetting and Cooling Performance of Polymer-Salt Hybrid Quench Medium with Conventional Quench Media. Experimental Heat Transfer, 8 (5): 464-492. 